\title{
THE STUDY OF RELATION BETWEEN THE GESTATIONAL AGE OF HUMAN FETUSES AND THE DIAPHYSEAL LENGTH OF FEMUR USING ULTRASONOGRAPHY
}

\section{Chaithra Rao B R *1, Sunkeswari Sreepadma 2, R N Kalghatgi ${ }^{3}$,}

${ }^{* 1}$ Assistant Professor, Department of Anatomy, Sapthagiri Institute of Medical Sciences and Research Centre, Bangalore, Karnataka, India.

${ }^{2}$ Associate Professor, Department of Anatomy, SDM College of Medical Sciences \& Hospital, Dharwad, Karnataka, India.

${ }^{3}$ Professor, Department of Anatomy, SDM College of Medical Sciences \& Hospital, Dharwad, Karnataka, India.

\section{ABSTRACT}

\begin{abstract}
Background and Objectives: Presently the most effective way to date pregnancy is by the use of ultrasound. The diaphyseal length of femur can be used as an additional parameter to estimate gestational age. The objective is to evaluate of the diaphyseal length of femur as a parameter to estimate the gestational age of the fetus at the time of examination.

Materials and Methods: It is a Prospective cross sectional study done on 152 antenatal women. Antenatal women of all gestational age from 15 to 40 weeks of gestation from the District of Dharwad, age ranging from 20 to 30 yrs were included. Subjects with maternal disease known to affect normal fetal growth such as chronic hypertension, gestational diabetes mellitus, anemia, hypothyroidism, etc. and history of recurrent miscarriages and of chronic medications, multiple gestations or other complications such as fetal growth restriction, preeclampsia, pregnancy induced hypertension, placenta previa, or major fetal abnormalities were excluded. The diaphyseal length of femur was measured by an experienced Ultrasonographer in a standardized manner. The study establishes the relationship of the diaphyseal length of femur in centimeters, with the advancing gestational age in weeks. We obtained correlation of the diaphyseal lengths of femur with the gestational age from 15 to 40 weeks.
\end{abstract}

Results: It was observed that the diaphyseal length of femur gradually increased from 15 weeks to 40 weeks of gestation. Normograms of diaphyseal lengths of femur can be constructed by the formula derived by this study for this particular geographical area. These normograms can be used to determine whether a given diaphyseal length of femur is normal or abnormal for a particular gestational age.

Conclusion: The relationship between the diaphyseal length of femur and the gestational age is linear and direct. The measurement of the diaphyseal lengths of femur (in $\mathrm{cm}$ ) can be an important additional parameter for estimating gestational age along with other parameters.

KEY WORDS: Down's syndrome; Femur; Fetal growth retardation; Fetus; Gestational age; Ultrasonography.

Address for Correspondence: Dr Chaithra Rao B R Assistant Professor, Department of Anatomy, Sapthagiri Institute of M edical Sciences and Research Centre, No 15, chikkasandra, Hesarghatta main road, Bangalore- 560090, Karnataka. India. Ph- +919916667709 Fax- 080283933404

E-Mail: chaithra.ra05@gmail.com

\section{Access this Article online}

\section{Quick Response code}

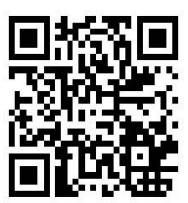

DOI: $10.16965 /$ ijar.2016.472
Web site: International Journal of Anatomy and Research

ISSN 2321-4287

www.ijmhr.org/ijar.htm
Received: 08 Nov 2016

Peer Review: 08 Nov 2016

Revised: 10 Nov 2016
Accepted: 20 Dec 2016

Published (0): 31 Jan 2017

Published (P): 31 Jan 2017 


\section{INTRODUCTION}

Fetal biometry is a methodology devoted to the measurement of several parts of fetal anatomy and their growth [1]. Fetal growth is an important determinant of future health. Fetal growth is influenced by a complex interplay of genetic, heritable and environmental factors and factors intrinsic to the conceptus [2]. Prenatal care is aimed at prevention of morbidity as well as mortality. During the past 30 years, new technology has been introduced to assess the fetus antepartum, including the electronic fetal monitoring, sonography and amniocentesis, with the fetus emerging as a patient in-utero [3]. Proper assessment of fetal well being requires accurate knowledge of gestational age of the fetus [4].

Recent advances in fetal imaging have been result of technological achievements in sonography and magnetic resonance imaging, with dramatic improvements in resolution and image display. A sonographic examination performed with the exacting recommended standards of American Institute of Ultrasound in medicine (2007) offers vital information about fetal anatomy, physiology, growth and well being [5]. Limbs are traditionally assessed during pregnancy as markers of fetal growth, nutrition, and gestational age. However, evaluation of fetal limbs and identification of abnormalities may also aid in the diagnosis of various chromosomal and non chromosomal conditions as well as narrow the differential diagnosis in cases where associated abnormalities have also been identified [6].

Fetal long bone lengths show a high correlation with gestational age and a low inter-observer variation, thus suggesting their usefulness in the assessment of the menstrual age as an alternative basis, when it is impossible to obtain reliable measurements of the biparietal diameter (BPD) (e.g. deep pelvic engagement of the vertex, dolichocephaly). Long bone length may be used for monitoring fetal growth and for diagnosing bone dysplasias[7].

Knowledge of gestational age is critical for obstetric decision making throughout the pregnancy. Gestational age and fetal weight are the two most important determinants of fetal viability and survival. Without the accurate knowledge of gestational age, diagnosis of such conditions as prolonged or post-term pregnancy and intrauterine growth restriction is often impossible. Appropriate management of preterm labor or a medically complicated pregnancy depends on an accurate estimate of fetal age and weight [3].

Because of its size, visibility, ease of measurement and less mobility than distal limb bones, the femur is preferred over other long bones as a means of predicting menstrual age.

Objective of the study: The study was conducted with the aim of evaluating the diaphyseal lengths of Femur of fetus through routine obstetric ultrasonography as a parameter to estimate the gestational age of the fetus at the time of examination.

\section{MATERIALS AND METHODS}

Source of Data: The study included 152 normal antenatal women attending antenatal clinic at the Department of Obstetrics and Gynecology, Sri Dharmasthala $M$ anjunatheshwara College of M edical Sciences and Hospital (SDM CM S \& H), Dharwad, during the period of study from December 2010 to January 2012. The research subjects were invited to participate under informed consent that was approved by Institutional Ethical Committee. The data collected at the time of examination included demographic variables like maternal age, height, current weight, educational and occupational status.

We studied the diaphyseal lengths of femur by Ultrasonography and assessed the same. The final study was taken up by defining the inclusion and exclusion criteria, so that the results (regression formula) will represent the ideal formula for healthy subjects representing Dharwad District area as observed in SDM CM S $\& H$, Dharwad. The inclusion and exclusion criteria for this study are mentioned below.

Inclusion Criteria: The fetuses of singleton pregnancies with the physical evidence of normal growth without gross structural abnormalities were included with the gestational age ranging from 15 to $40 \mathrm{wks}$. All research subjects were healthy Indian women from the District of Dharwad in order to represent this particular geography. Their age ranged 
from 20 to 30 yrs with weight of 50 to $60 \mathrm{kgs}$ at the time of examination and their height was between $5 \mathrm{ft}$ and $5 \mathrm{ft} 6$ inches ( $\left.5^{\prime} 6^{\prime \prime}\right)$. The subjects had a regular menstrual history with well known LM P. Only primigravida and second gravida were included. All participants had uncomplicated pregnancies with the intact fetal membranes, normal amniotic fluid volume and absence of labor at the time of examination.

Exclusion Criteria: The cases of maternal disease known to affect normal fetal growth such as chronic hypertension, gestational diabetes mellitus, anemia, hypothyroidism, etc. and history of recurrent miscarriages and of chronic medications were excluded. The pregnancies with multiple gestations or other complications such as fetal growth restriction, preeclampsia, pregnancy induced hypertension, placenta previa, or major fetal abnormalities were excluded. The maternal habits like smoking known to affect growth of fetus were also excluded. Repeat measurement on same fetus was excluded.

\section{The Scanners and Transducers used:}

The grey scale real time Ultrasonographic examinations were performed using a PHILIPSHD6 Ultrasound System [fig. 1]. All scans were performed using a $3.5 \mathrm{M} \mathrm{Hz}$ curvilinear transducer (C5-2 Broadband Curved Array Transducer [fig.2]). The hard copy of images was acquired using thermal printer and photographs.

\section{The Sonographic Technique used for measure- ment of Femur length:}

The subjects were scanned with a moderately distended bladder in supine position. The transducer was placed on the skin surface after applying the coupling agent.

Femur length: The long axis of the fetus is identified first, and then the transducer was then turned 900 to produce a cross sectional image of the fetal trunk. The transducer was then moved down the fetus, maintaining this angle, to the fetal pelvis. Since the fetal femur is usually flexed, the transducer was rotated 450 towards the fetal abdomen in order to visualize the long axis of the femur. The full length of the femur was identified and in a plane as close as possible to right angles to the ultrasound beam. A straight measurement was made from the centre of one end of the diaphysis to the other, disregarding any curvature [fig. 3]. Care was taken to avoid tangential sections, which would for shorten the femur. In the third trimester, particular attention was paid not to include the distal femoral epiphysis, which would artificially lengthen the measurement. All measurements were made using electronic calipers.

Calculation of Gestational Age: The gestational age was calculated from the first day of last menstrual period, and corrected for cycle length, i.e. corresponding number of days were added or subtracted according to menstrual cycle length shorter or longer than 28 days respectively. The fetal age was confirmed by either first trimester or early second trimester sonographic scans. The age estimation in first trimester was based on crown-rump length (CRL) measurements and in second trimester was determined with the use of biparietal diameter (BPD), head circumference $(\mathrm{HC})$ and abdominal circumference (AC).

Fig. 1: Philips HD6 Ultrasound System.

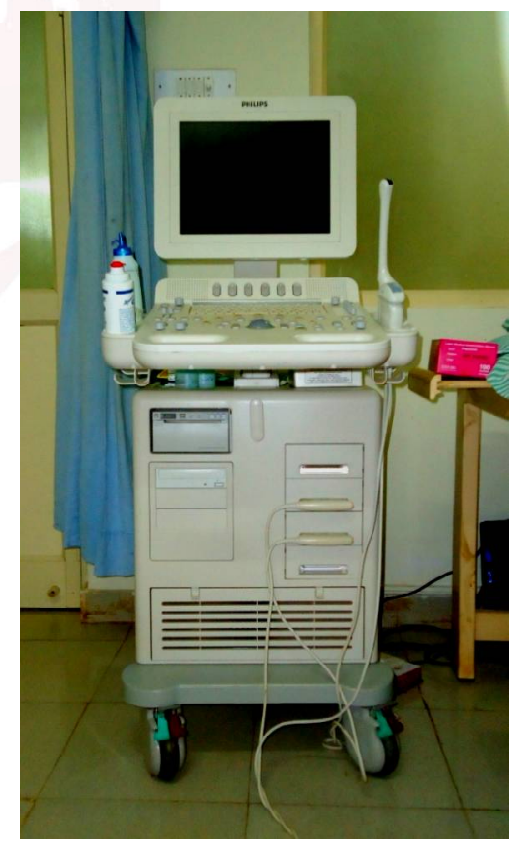

Fig. 2: Curvilinear transducer of $3.5 \mathrm{M} \mathrm{Hz}$.

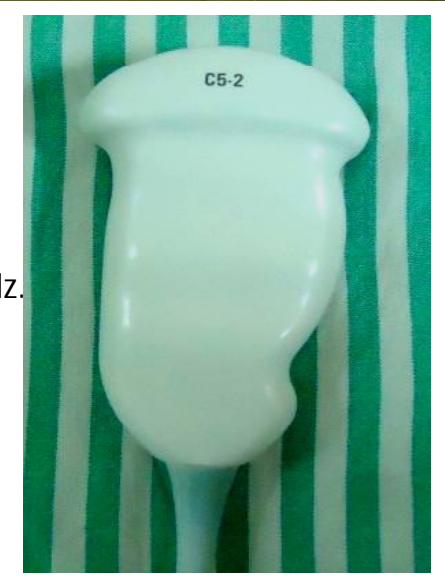


Fig. 3: Ultrasonographic image of diaphyseal length of femur.

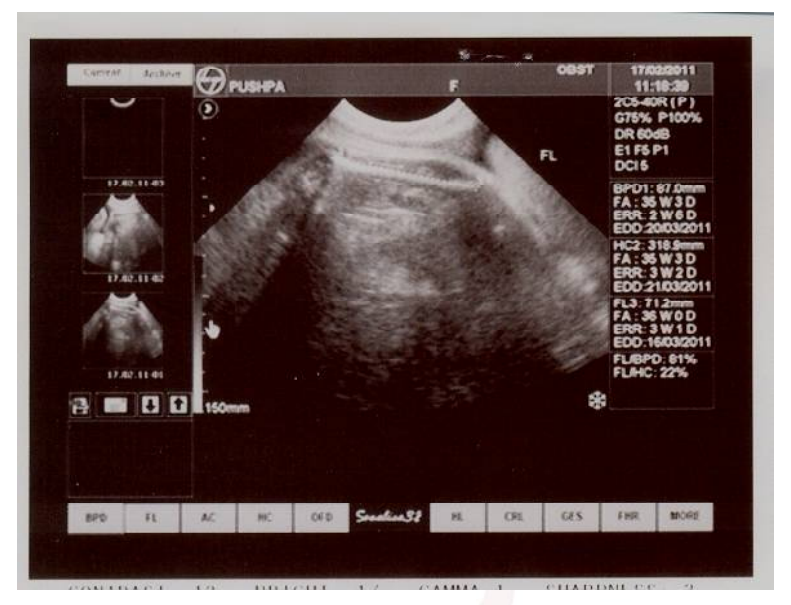

\section{Statistical Analysis:}

Study design: It comprised of prospective cross sectional study consisting of 152 normal antenatal women. The study protocol was approved by the Institutional Ethical Committee. A pilot study was conducted including 100 subjects. The mean length of femur was $59.862 \mathrm{~mm} \pm$ SD of 15.540. Considering the aerror of $5 \%$ and a precision of $10 \%$ of the mean $[L=5.986]$, the sample size works out to be 27 subjects [sample size $=4 *$ variance $/$ L2]. Therefore after adding $10 \%$ [2.7], the sample size is 29.7 rounded off to 30 subjects. But 152 cases were included because, the larger the sample size, the greater precision the resulting conclusions will have.

Statistical methods: The mean values of femur length (FL) in $\mathrm{cm}$, along with respective Standard Deviation (SD) were computed for each gestational age from 15 to $40 \mathrm{wks}$. The $95 \%$ confidence interval was also calculated. The correlation and regression analysis has been carried out to quantify the relationship between the gestational age in weeks and femur length $(\mathrm{FL})$ in $\mathrm{cm}$.

Statistical software: The statistical software namely SPSS 10.0 and ANOVA was used for the analysis of the data and Microsoft Word and Excel have been used to generate graphs, tables etc.

\section{RESULTS}

The number of measurements for each week of gestational age: The number of measurements studied in each gestational week ranged from 1 to 19. A total of 152 measurements were obtained from as many cases as shown in fig 4.
Relationship between the gestational age and the diaphyseal length of femur: The results of measurements of the diaphyseal length of femur at each week of gestational age from 15- 40 weeks are shown in table 1.

It is observed that the diaphyseal length of femur increased from $1.71 \mathrm{~cm}$ at 16 weeks to $7.56 \mathrm{~cm}$ at 40 weeks of gestation.

The diaphyseal length of femur in fetuses of subjects from 15 to 40 weeks of gestation is plotted with gestational age and it is observed that there is a linear relationship between the diaphyseal length of femur in $\mathrm{cm}$ and the gestational age in weeks (fig 5). The mean values of diaphyseal length of femur (in $\mathrm{cm}$ ) plotted against advancing gestational age from 15 to 40 wks showed a perfect increasing linear trend with increasing gestational age (fig 6).

It is observed from $95 \%$ confidence interval that gestational age can be accurately predicted from the diaphyseal length measurements of femur. From the results of table 2 it can be seen that, 1. A significant and positive relationship was observed between gestational age and the diaphyseal length of femur $(r=0.9893, p<0.05)$ at $5 \%$ level of significance as shown in table 2 . It means that the gestational age and the diaphyseal length of femur are dependent on each other. The diaphyseal length of femur (in $\mathrm{cm}$ ) increases with increasing gestational age (in weeks).

2. The correlation coefficient between the gestational age and the diaphyseal length of femur is 0.9893 and t-value is 82.9932 . Therefore there is a positive correlation observed between the gestational age and the diaphyseal length of femur. This shows that the diaphyseal length of femur is a better predictor of gestational age.

\section{Regression analysis of relationship between} the gestational age and the diaphyseal length of femur: The Simple Linear Regression Analysis was applied to assess the dependent variable, Gestational Age by another independent variable Femur Length in total of 152 cases as shown in table 3. The Regression Co-efficient constant is 5.994. The Regression Co-efficient for $F L$ is 4.370 . The data show that the diaphyseal length of femur is directly related to 
gestational age, with simple linear regression modeling, yielding the equation in the form of $\mathrm{y}=\mathrm{a}+\mathrm{b} 1 \mathrm{x} 1$

where ' $y$ ' is the dependent variable, ' $a$ ' is the regression coefficient constant, b1 is regression coefficient for independent variable and $x 1$ is the independent variable itself i.e.

\section{$\mathrm{GA}=\mathrm{a}+\mathrm{b} 1[\mathrm{FL}]$}

where GA is the gestational age in weeks and $\mathrm{FL}$ is the diaphyseal length of femur in $\mathrm{cm}$. Therefore,

\section{$\mathrm{GA}=5.994+4.370[\mathrm{FL}]$}

Hence the gestational age can be estimated by the derived formula.

The influence or impact of the diaphyseal length of femur is found to be significant and positive on gestational age $(p<0.05)$. It means that, the diaphyseal length of femur is the one of best predictors of gestational age.

Table 1: Effect of advancing gestational age on the diaphyseal lengths of femur.

\begin{tabular}{|c|c|c|c|}
\hline $\begin{array}{c}\text { Gestational age in } \\
\text { weeks }\end{array}$ & $\begin{array}{l}\text { No. of } \\
\text { cases }\end{array}$ & $\%$ of cases & Mean of $\mathrm{FL}$ \\
\hline 15 & 1 & 0.66 & 1.73 \\
\hline 16 & 1 & 0.66 & 1.71 \\
\hline 17 & 5 & 3.29 & 2.25 \\
\hline 18 & 3 & 1.97 & 2.82 \\
\hline 19 & 4 & 2.63 & 3.12 \\
\hline 20 & 10 & 6.58 & 3.29 \\
\hline 21 & 15 & 9.87 & 3.58 \\
\hline 22 & 8 & 5.26 & 3.91 \\
\hline 23 & 9 & 5.92 & 4.11 \\
\hline 24 & 11 & 7.24 & 4.26 \\
\hline 25 & 7 & 4.61 & 4.61 \\
\hline 26 & 2 & 1.32 & 4.67 \\
\hline 27 & 4 & 2.63 & 5.01 \\
\hline 28 & 5 & 3.29 & 5.22 \\
\hline 29 & 5 & 3.29 & 5.55 \\
\hline 30 & 2 & 1.32 & 5.83 \\
\hline 31 & 4 & 2.63 & 5.94 \\
\hline 32 & 3 & 1.97 & 6.13 \\
\hline 33 & 3 & 1.97 & 6.54 \\
\hline 34 & 3 & 1.97 & 6.74 \\
\hline 35 & 6 & 3.95 & 6.69 \\
\hline 36 & 11 & 7.24 & 6.91 \\
\hline 37 & 19 & 12.5 & 7.07 \\
\hline 38 & 7 & 4.61 & 7.08 \\
\hline 39 & 3 & 1.97 & 7.46 \\
\hline 40 & 1 & 0.66 & 7.56 \\
\hline
\end{tabular}

Table 2: Correlation co-efficient between the gestational age (in wks) with the diaphyseal length of femur [in $\mathrm{cm}$ ] by karl pearson's correlation method ( $n=152)$.

\begin{tabular}{|c|c|c|c|}
\hline \multirow{2}{*}{ Lengths (in cm) } & \multicolumn{3}{|c|}{ Correlation coefficient between } \\
\cline { 2 - 4 } & $\begin{array}{c}\text { Correlation } \\
\text { coefficient }(r)\end{array}$ & t-value & p-value \\
\hline Femur length & 0.9893 & 82.9932 & $0.0000^{*}$ \\
\hline
\end{tabular}
$* p<0.05$

Table 3: simple linear regression of the gestational age by the diaphyseal length of femur [in $\mathrm{cm}$ ] in total samples.

\begin{tabular}{|c|c|c|c|c|c|c|}
\hline $\begin{array}{c}\text { Independent } \\
\text { variable }\end{array}$ & $\begin{array}{c}\text { Regression } \\
\text { coefficient }\end{array}$ & $\begin{array}{c}\text { SE of } \\
\text { regression } \\
\text { coefficient }\end{array}$ & t-value & p-value & F-value & $\begin{array}{c}\text { Regression } \\
\text { equation }\end{array}$ \\
\hline Constant & 5.994 & 0.2819 & 21.26 & $0.000^{*}$ & 6887.9 & $\begin{array}{c}\text { GA }= \\
5.994+4.37(\mathrm{FL})\end{array}$ \\
\hline Femur length & 4.37 & 0.0527 & 82.993 & $0.000^{*}$ & & . \\
\hline
\end{tabular}

$* p \varangle 0.05$

Fig. 4: Distribution of subjects according to number of cases in each week of gestation

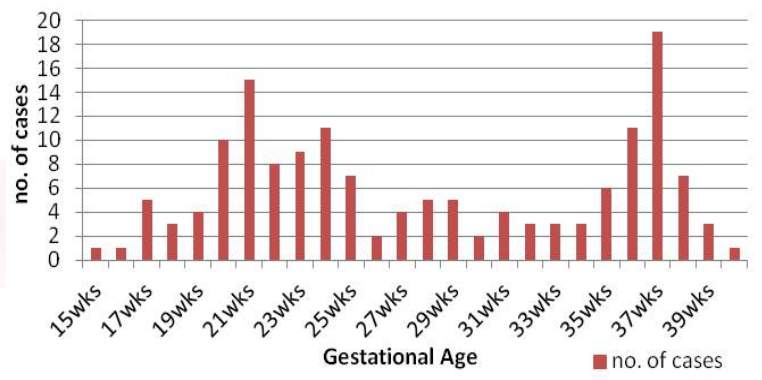

Fig 5: Plot of the diaphyseal lengths of femur (in $\mathrm{cm}$ ) with gestational age (in weeks) of all cases.

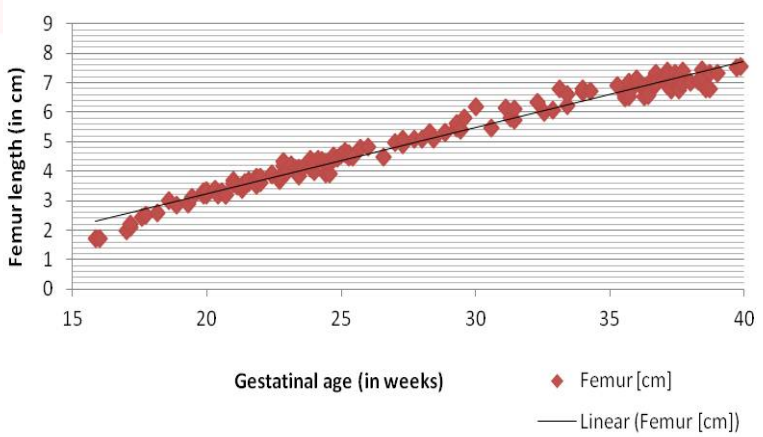

Fig. 6: Mean values of diaphyseal lengths of femur (in $\mathrm{cm}$ ) plotted against advancing gestational age from 15 to 40 wks.

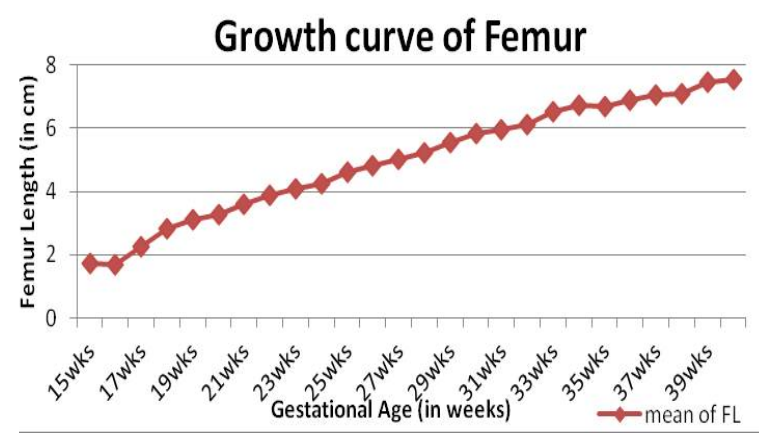


Fig. 7: Relationship of the gestational age (in weeks) and the diaphyseal length of femur (in $\mathrm{cm}$ ) by simple linear regression equation.

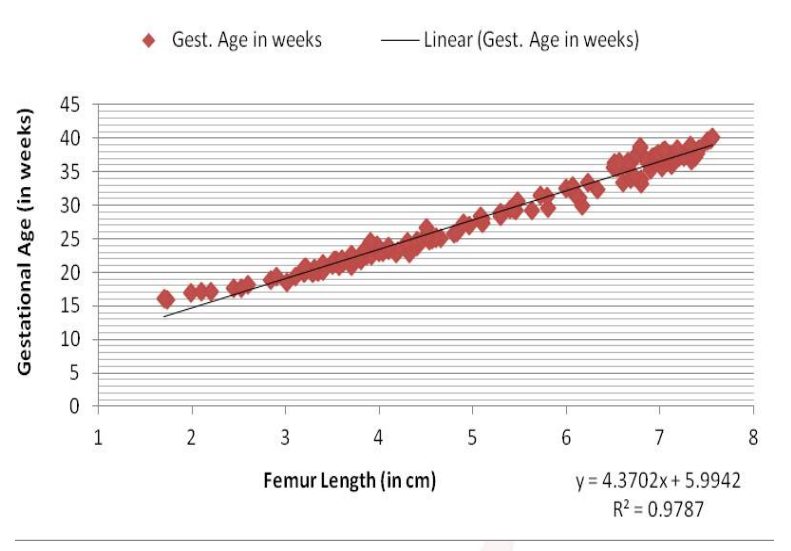

\section{DISCUSSION}

The advent of the ultrasound has revolutionized obstetric management. We are no more in the watchful era of "watchful expectancy with masterly inactivity". We have moved into the age of "watchful expectancy with masterly activity" and this has been made possible by ultrasound. Confirmation of pregnancy and its viability, determination of gestational age, growth abnormalities, early diagnosis of congenital anomalies, evaluation of placenta and its abnormalities are some of the uses of ultrasonography in obstetrics. Fetal therapy has now become possible using ultrasound guided procedures [8].

Improved instrumentation with the latest high resolution dynamic imaging equipment, coupled with increased diagnostic capability have ushered in a new era in the identification of fetal anatomy more explicitly, employing measurement of many more growth parameters for the estimation of gestational age [9].

In the present study we have assessed the relationship of sonographically measured diaphyseal lengths of femur (in $\mathrm{cm}$ ) with gestational age (in weeks) and the growth pattern of femur with advancing gestational age. The study showed that the diaphyseal lengths of femur (in $\mathrm{cm}$ ) increases steadily with increasing gestational age (in weeks) in a linear fashion.

The results of the present study are consistent with the observations made by authors of previous studies.

P. Rosati et al studied the relationships between femur length vs. BPD and GA. In a random sample group of 400 subjects, a regression analysis was performed to evaluate the relationship between BPD in $\mathrm{mm}$ and gestational age (GA) in days vs. FL in $\mathrm{mm}$, in the different gestational periods. An expected femur (EFL) wasthen calculated from the regression equation for each $B P D$ and GA. Linear equations turned out to be the best models for describing the relationship between femur (EFL $=-16.92108+0.4569402 \times$ $B P D+0.171617 \times G A)$ vs. BPD and GA for the sample group of 400 fetuses [10].

Hadlock F. P. et al studied the relation between fetal femur length and gestational age by crosssectional analysis of 338 normal fetuses (1240 wks) using real time sonography. Regression analysis of gestational age/ femur length relation was carried out on each group using the linear, linear quadratic and linear cubic models and the optimal model was determined from $\mathrm{r} 2$ measurements. The linear quadratic function was the optimal model for predicting menstrual age from femur length ( $r 2=97.3 \%$ ). The regression equation for this data is menstrual age = $10.38+0.2256 \mathrm{FL}+0.001948 \mathrm{FL} 2$, where gestational age is in weeks and $\mathrm{FL}$ is in $\mathrm{mm}$ [11].

S. Gabrielli et al studied the relationship between FL and GA using a regression model in a total of 149 early pregnancies. A second degree polynomial equation was found to describe the data adequately, $\mathrm{FL}=6.645116$ " $0.18346 \times \mathrm{GA}$ $+0.002102 \times \mathrm{GA} 2$, where $\mathrm{FL}$ is in $\mathrm{mm}$ and $\mathrm{GA}$ is in days [12].

A. Zorzoli et al measured the fetal femur in 296 pregnant women at 64- 108 days gestational age, using vaginal sonography. Limb measurements correlated significantly with gestational age, the best description being achieved by a linear regression for all segments. Multiple regression showed that each limb bone correlated independently with both GA and BPD, $\mathrm{FL}=-8.26+0.0669 \mathrm{GA}+0.537 \mathrm{BPD}$ where $\mathrm{GA}$ is in days, FL and BPD are in $\mathrm{mm}$ [13]. C. Exacoustos et al studied the growth patterns of fetal limbs, measurements of femur, made by ultrasound and related it to gestational age in 2317 normal singleton pregnancies at 13 to 40 wks of gestation. The regression analysis was used to establish relationships between long bone length and gestational age. The second degree polynomial equation turned out to be the 
best model describing the relationship between femur length $(F L=-37.15+4.159 \mathrm{GA}-0.033$ $\mathrm{GA} 2 ; \mathrm{r}=0.994$; residual $\mathrm{SD}=2.085 ; \mathrm{P}<0.0001$ ) and gestational age in weeks [7].

L. J. Salomon et al constructed new reference charts and equations for fetal FL, BPD, head circumference $(\mathrm{HC})$ and abdominal circumference (AC) using a large sample (19647) of fetuses examined at 15 to 40 wks gestation. Raw data were fitted satisfactorily with a cubic polynomial model for each biometric parameter as follows: $\mathrm{FL}=-27.085+2.9223 \times \mathrm{GA}+0.0148$ $\times G A 2-0.0006 \times G A 3(R 2=96.33)$, where $F L$ is in $\mathrm{mm}$ and $\mathrm{GA}$ is in weeks [14].

T. N. Leung constructed new reference charts and equations for fetal biometry in Hong Kong ethnic Chinese population involving 709 women with singleton pregnancies between 12 to 40 completed weeks of gestation. The fetal biometric measurements recorded included $B P D, A C$, $\mathrm{HC}$ and $\mathrm{FL}$. For each measurement, regression model were fitted to estimate the mean and SD at each $\mathrm{GA}$. The raw data were fitted to the $\mathrm{GA}$ in weeks satisfactorily with a cubic polynomial model. The formula for the regression model of $\mathrm{FL}$ and its correlation co-efficient (R2) are as follows: $\mathrm{FL}=$ "4.445082 +0.492073 ×GA " 0.0067 $\times \mathrm{GA} 2+0.000042 \times \mathrm{GA} 3(\mathrm{R} 2=0.986)$, where FL is in $\mathrm{cm}$ and $\mathrm{GA}$ is in weeks [15].

In the present study the simple linear regression equation derived for the calculation of gestational age using the diaphyseal length of femur is

$$
\mathrm{GA}=5.994+4.370 \text { [FL], }
$$

where GA is the gestational age in weeks and $F L$ is the diaphyseal length of femur in $\mathrm{cm}$.

Diaphyseal lengths plotted against gestational age showed a linear growth curves except in the later part of intrauterine life when the curve is almost horizontal due to minimal growth. Similar observations were made in the previous studies $[4,11,13,14,16,17,18,19,20]$. Accurate pregnancy dating is important to establish gestational age for evaluation of fetal growth and prediction of the date of delivery.

Limitations of the study: The present study is a cross-sectional study design, which is made up of observations on different individuals. It is not a true growth curve of femur as these can only be obtained from serial measurements taken on the same patient throughout gestation. So, it may not provide a clear understanding in individual growth patterns. However, it is a reasonable approximation of a true growth curve of femur. Longitudinal growth curves of femur can be constructed from serial measurements taken on the same patient throughout pregnancy.

Accuracy of measurements of femur depends on making a perpendicular scan of the long bone and care should be taken in acquisition and interpretation of the images to prevent spurious measurements. All examinations were performed using the same equipments and by the same examiner to minimize these measurement errors.

The parameter for long bone length may vary among different population groups. Population specific normograms may be derived from large sample sizes. The long bone growth curves may be different for different population groups.

\section{CONCLUSION}

The relationship between the diaphyseal length of femur and the gestational age is linear and direct. Measurement of the diaphyseal lengths of femur can be an important additional parameter for estimating gestational age along with other parameters especially from 15 to 40 weeks of gestation. The diaphyseal lengths of femur (in $\mathrm{cm}$ ) increases with increasing gestational age (in weeks). Normograms of diaphyseal lengths of femur can be constructed by the formula derived by this study for this particular geographical area. These normograms can be used to determine whether a given diaphyseal length of femur is normal or abnormal for a particular gestational age. Thoughtful attention to technical details and correlation of the diaphyseal lengths of femur with the gestational age should facilitate the detection of abnormal diaphyseal lengths of femur associated with Down Syndrome, Intra Uterine Growth Restriction, M acrosomia, Skeletal Dysplasias, etc. in early stages.

Sonographic measurement of diaphyseal lengths of femur is relatively simple and is clinically useful. It enables the evaluation and detection of fetal growth abnormalities that can signifi- 
cantly affect the management and outcome of pregnancy. Determining the diaphyseal lengths of femur may be helpful in the diagnosis of abnormalities; shortened and abnormal long bones are seen in skeletal dysplasias and intra uterine growth restrictions. Increased length is observed in macrosomia of varied causes.

\section{Conflicts of Interests: None}

\section{REFERENCES}

[1]. Shehzad K, Ali M, Zaid S. Fetal Biometry. Pak J Med Sci 2006;22(4):503-8.

[2]. Silva LM, Jansen PW, Steegers EAP, Jaddoe VWV, Arends LR, Tiemeier $\mathrm{H}$ et al. M other's educational level and fetal growth: the genesis of health inequalities. Int. J. Epidemiol 2010;39(5):1250-61.

[3]. Johnson TRB, Gregory KD, Niebyl JR. Preconception and Prenatal Care: Part of continuum. In: Gabbe SG, Niebyl JR, Simpson JL, editors. Obstetrics: Normal and Problem Pregnancies. 5th ed. Philadelphia: Churchill Livingstone Elsevier; 2007. p. 111-37.

[4]. Khan Z, Faruqi NA. Determination of Gestational Age of Human Foetuses From Diaphyseal Lengths Of Long Bones - A Radiological Study. J.Anat.Soc. India; 2006;55(1): 67-71.

[5]. Cunningham FG, Leveno KJ, Bloom SL, Hauth JC, Rouse DJ, Spong CV. Fetal Imaging. In: Williams Obstetrics. 23th ed. USA:The M cGraw Hill Companies; 2010. p. 349-71.

[6]. Rice KJ, Ballas], Lai E, Hartney C, Jones M C, Pretorius $\mathrm{DH}$. Diagnosis of fetal limb abnormalities before 15 weeks: cause for concern. J Ultrasound Med 2011;30(7):1009-19.

[7]. Exacoustos C, Rosati P, Rizzo G, Arduini D. Ultrasound measurements of fetal limb bones. Ultrasound Obstet Gynecol 1991;1(5):325-30.

[8]. Malhotra N, Suresh S. Physics of Ultrasound. In: Malhotra N, editor. Ultrasound in obstetrics and gynaecology. 3rd ed. New Delhi: Jaypee Brothers Medical publishers; 2001. p. 10-6.

[9]. Gupta K. Measurement of foetal parameters. In: Malhotra N, editor. Ultrasound in obstetrics and gynaecology. 3rd ed. New Delhi: Jaypee Brothers Medical publishers; 2001. p. 92-8.

[10]. Rosati P, Guariglia L, Capelli G. A new mathematical formula for predicting long bone length in early pregnancy. Ultrasound Obstet Gynecol 2002;19(2):184-9.
[11]. Hadlock FP, Harrist RB, Deter RL, Park SK. Fetal femur length as a predictor of menstrual age: sonographically measured. AJR Am J Roentgenol 1982;138(5):875-8.

[12]. Gabrielli S, Falco P, Pilu G, Perolo A, Milano V, Bovicelli L. Can transvaginal fetal biometry be considered a useful tool for early detection of skeletal dysplasias in high-risk patients? Ultrasound Obstet Gynecol 1999;13(2):107-11.

[13]. Zorzoli A, Kustermann A, Caravelli E, Corso FE, Fogliani R, Aimi G et al. Measurements of fetal limb bones in early pregnancy. Ultrasound Obstet Gynecol 1994;4(1):29-33.

[14]. Salomon LJ, Duyme M, Crequat], Brodaty G, Talmant $C$, Fries $\mathrm{N}$ et al. French fetal biometry: reference equations and comparison with other charts. Ultrasound Obstet Gynecol 2006;28(2):193-8.

[15]. Leung TN, Pang M W, Daljit SS, Leung TY, Poon CF, Wong SM et al. Fetal biometry in ethnic Chinese: biparietal diameter, head circumference, abdominal circumference and femur length. Ultrasound Obstet Gynecol 2008;31(3):321-7.

[16].Kurmanavicius J, Wright EM, Royston P, Zimmermann R, Huch R, Huch A et al. Fetal ultrasound biometry: Abdomen and femur length reference values. Br J Obstet Gynaecol 1999;106(2):136-43.

[17]. Merialdi M, Caulfield LE, Zavaleta N, Figueroa $A$, Costigan KA, Dominici $F$ et al. Fetal growth in Peru: comparisons with international fetal size charts and implications for fetal growth assessment. Ultrasound Obstet Gynecol 2005;26(2):1238.

[18]. Rosati P, Guariglia L. Trans-vaginal fetal biometry in early pregnancy. Early Hum Dev 1997;49(2):916.

[19]. Sananes N, Guigue V, Kohler M, Bouffet N, Cancellier $M$, Hornecker F et al. Use of Z-scores to select a fetal biometric reference curve. Ultrasound Obstet Gynecol 2009;34(4):404-9.

[20]. Verburg BO, Steegers EA, De Ridder M, Snijders RJ, Smith E, Hofman A et al. New charts for ultrasound dating of pregnancy and assessment of fetal growth: longitudinal data from a population-based cohort study. Ultrasound Obstet Gynecol 2008;31(4):388-96.
How to cite this article:
Chaithra Rao B R, Sunkeswari Sreepadma, R N Kalghatgi. THE STUDY OF RELATION BETWEEN THE GESTATIONAL AGE OF HUM AN FETUSES AND THE DIAPHYSEAL LENGTH OF FEMUR USING ULTRASONOGRAPHY. Int J Anat Res 2017;5(1):3342-3349. DOI: $10.16965 /$ ijar.2016.472 